\title{
QUEDAS EM NONAGENÁRIOS E CENTENÁRIOS DURANTE A PANDEMIA
}

\section{DA COVID-19}

Gabriela Guimarães Oliveira; PUCRS; oliveira_gabriela@hotmail.com; Josemara de Paula Rocha; PUCRS; josemara.rocha@hotmail.com;

Liziane da Rosa Camargo; PUCRS; liziane_camargo@hotmail.com; Ângelo José Gonçalves Bós; PUCRS; angelo.bos@pucrs.br

\section{RESUMO}

Introdução: Embora a estratégia restritiva seja fundamental para controlar a pandemia da COVID-19, ela pode causar diminuição da funcionalidade, que predispõe às quedas, principalmente em nonagenários e centenários. Objetivos: Observar a frequência de quedas em nonagenários e centenários durante o isolamento social. Métodos: Estudo observacional e transversal envolvendo nonagenários e centenários participantes do Projeto Atenção Multiprofissional ao Longevo (AMPAL). A avaliação foi feita por Smartphone entre abril e agosto/2020, incluindo características sociodemográficas e clínicas que incluiu o relato de queda nas últimas duas semanas, Prática de Atividade Física (PAF), Teste de Levantar e Sentar (TLS - não satisfatório <5 repetições em 15s), facilidade para levantar da cadeira e Escala de Depressão Geriátrica (GDS) de 5 pontos (alterado $\geq 2$ pontos). Resultados: Entre os 59 participantes, $20 \%$ caíram nas últimas semanas. Frequência essa maior entre mulheres (22\%, homens 14\%), entre 95-99 anos (25\%), que não moravam sozinhos (23\%, contra 9\%), com GDS alterado (33\%, contra 15\%), não praticavam atividade física (21\%, contra $20 \%)$, referiram ser \pm fácil ou difícil levantar-se da cadeira (22\%) e TLS não satisfatório (23\%). Nenhum participante que teve TSL satisfatório caiu (0\%). Entre as pessoas que caíram $42 \%$ referiu que a frequência de queda piorou durante a pandemia da COVID-19. Conclusão: Durante o período de restrição social, a natureza multicausal das quedas pareceu se manter entre os nonagenários e centenários. Embora não significativo estatisticamente, diferenças na frequência de quedas foram observadas entre gênero, idade, morar com ou sem companhia, PAF, sintomas depressivos, função e força de membros inferiores.

Palavras-chave: Acidentes por quedas; Idoso de 80 anos ou mais; Infecções por Coronavirus.

Agradecimentos: O presente trabalho foi realizado com apoio da Coordenação de Aperfeiçoamento de Pessoal de Nível Superior - Brasil (CAPES) - Código de Financiamento 001. 